\title{
Long- and short-type double-balloon enteroscopy-assisted therapeutic ERCP for intact papilla in patients with a Roux-en-Y anastomosis
}

\author{
Takao Itoi - Kentaro Ishii - Atsushi Sofuni · Fumihide Itokawa - Takayoshi Tsuchiya • \\ Toshio Kurihara $\cdot$ Shujiro Tsuji $\cdot$ Nobuhito Ikeuchi $\cdot$ Katsumasa Fukuzawa \\ Fuminori Moriyasu $\cdot$ Akihiko Tsuchida
}

Received: 10 August 2009/ Accepted: 12 November 2009/Published online: 26 October 2010

(C) The Author(s) 2010. This article is published with open access at Springerlink.com

\begin{abstract}
Background There have been a few previous reports on attempted double-balloon endoscopy (DBE)-assisted endoscopic retrograde cholangiopancreatography (ERCP) in patients with Roux-en-Y anastomosis and an intact papilla. This study was designed to evaluate the usefulness of DBE-assisted ERCP in patients with Roux-en-Y anastomosis and an intact papilla of Vater.

Methods Thirteen DBE procedures were performed in nine patients who had undergone Roux-en-Y reconstruction combined with eight total gastrectomies and one partial gastrectomy. Both short-type and long-type DBE were used. Long-type DBE was replaced with a conventional forward-viewing upper endoscope after reaching the papilla. Technical success rate, measurement of procedure times, and adverse events were evaluated in the retrospective study.

Results In all cases, the scopes could reach the papilla. The mean time required to reach the papilla was 48 (range, 13-90) min. There was a statistically significant difference with the short and long scope $(29.0 \pm 19.2 \mathrm{~min}$ vs. $64.8 \pm 24.7 \mathrm{~min}$, respectively; $P=0.044)$. The success rate of bile duct cannulation, resulting in achieving therapeutic ERCP on the first session was $66.7 \%$ (6/9). The mean procedural time in the successful cases was 128
\end{abstract}

T. Itoi $(\bowtie) \cdot$ K. Ishii - A. Sofuni · F. Itokawa - T. Tsuchiya ·

T. Kurihara $\cdot$ S. Tsuji $\cdot$ N. Ikeuchi $\cdot$ K. Fukuzawa $\cdot$ F. Moriyasu

Department of Gastroenterology and Hepatology,

Tokyo Medical University, 6-7-1 Nishishinjuku, Shinjuku-ku,

Tokyo 160-0023, Japan

e-mail: itoi@tokyo-med.ac.jp

A. Tsuchida

Third Department of Surgery, Tokyo Medical University, Tokyo, Japan (range, 47-183) min. Finally, therapeutic ERCP was achieved in all nine cases. There was one adverse event in which retroperitoneal perforation during lithotripsy, but that was successfully treated by conservative therapy alone. Conclusion DBE-assisted ERCP seems to be a promising option to perform therapeutic ERCP for intact papilla in patients with a Roux-en-Y anastomosis.

Keywords Double-balloon enteroscopy .

Endoscopic retrograde cholangiopancreatography .

Endoscopic biliary stenting $\cdot$ Endoscopic stone removal

\author{
Abbreviations \\ DBE Double balloon enteroscopy \\ ERCP Endoscopic retrograde cholangiopancreatography \\ ES Endoscopic sphincterotomy \\ PTBD Percutaneous transhepatic biliary drainage
}

Roux-en-Y reconstruction is frequently performed for surgical reconstruction, especially when total or subtotal gastrectomy, gastric bypass surgery, pylorus-preserving pancreaticoduodenectomy, and biliary tract or liver surgery is performed [1]. In general, the presence of a Roux-en-Y anastomosis has been thought to preclude endoscopic access for diagnostic and therapeutic endoscopic retrograde cholangiopancreatography (ERCP) because the long length efferent and afferent limbs must be traversed to reach the major papilla. Furthermore, the acute angle of anastomosis of the afferent limb is frequently difficult to navigate. Even if the endoscope reaches a terminal portion of the afferent limb, selective duct cannulation or therapy via an intact papilla is considered to be difficult compared with accessing a biliopancreatoenteric anastomosis site. 
To date, ERCP in patients with Roux-en-Y anastomosis has been reported using not only a standard side-viewing duodenoscope but also using pediatric or adult colonoscopes. However, the ratio of reaching the end of afferent limb was not high. Recently, double-balloon endoscopy (DBE), which was first introduced by Yamamoto et al. [2], has been used not only for diagnostic and therapeutic endoscopy of the small bowel but also for ERCP-related procedures. However, there have been a few previous reports on attempted DBE-assisted ERCP in patients with Roux-en-Y anastomosis and an intact papilla. In the present study, we evaluated the usefulness of DBE-assisted ERCP in patients with Roux-en-Y anastomosis and an intact papilla.

\section{Patients and methods}

Thirteen DBE procedures were performed in nine patients (5 men and 4 women, 7 with bile duct stones, 1 with malignant biliary stricture due to lymph node metastasis of recurrent gastric cancer, and 1 with benign biliary stricture due to pancreatic abscess) with Roux-en-Y reconstruction combined with eight total gastrectomies and one partial gastrectomy for gastric cancer between June 2006 and January 2009 at Tokyo Medical University Hospital (Table 1). The mean age of these 9 patients was 67 (range, 57-77) years. The patients enrolled had not previously undergone any endoscopic procedures. The institutional review board approved this study. Written informed consent was obtained from all patients for DBE.

\section{DBE procedures}

All procedures were performed by a single endoscopist (TI). The procedure was performed under conscious sedation using a combination of flunitrazepam (mean dosage, 4 (range, 1-5) $\mathrm{mg}$ ) and pethidine $(50 \mathrm{mg})$. The patients were placed in semiprone or prone position.

In this study, until April 2007, we used a long-type DBE (working length 2,000 mm, EN-450T5, Fujinon Co. Ltd., Saitama, Japan). Later, a short-type DBE was used (working length 1,520 mm, EC-450B15, Fujinon). Detailed specifications of both therapeutic enteroscopes and the overtube are described in Table 2. When we used the longtype DBE, it was replaced during the procedure with a conventional forward-viewing upper endoscope (GIF-XQ 240, outer diameter $9 \mathrm{~mm}$, working channel $2.8 \mathrm{~mm}$, working length $1,030 \mathrm{~mm}$, Olympus Medical Systems, Tokyo, Japan) because long accessories were not commercially available in Japan at that time. Specifically, the long-type DBE was removed through the indwelling overtube with its balloon inflated after reaching the papilla. Then, an aperture, approximately $12 \mathrm{~mm}$, was made in the overtube at a point $100 \mathrm{~cm}$ from its tip on the side opposite to the pressure line to enable the balloon to remain inflated for insertion of a forward viewing upper endoscope. Then, the upper endoscope was inserted through the overtube (Fig. 1). If the distance within the body to the tip of the overtube was more than $100 \mathrm{~cm}$ in length, we retracted it carefully using fluoroscopy to prevent tube dislocation until the total length of the overtube remaining within the body was less than approximately $100 \mathrm{~cm}$; then the aperture was made.

\section{ERCP procedures}

A standard catheter (ERCP catheter, MTW Co. Ltd, Düsseldorf, Germany) and a tapered catheter (PR-110Q, Olympus Medical Systems) were used for initial cannulation. In cases requiring an endoscopic sphincterotomy (ES), a $0.025^{\prime \prime}$ guidewire was placed after deep cannulation into the bile duct; then a sphincterotome (KD-6Q, Olympus Medical Systems) was advanced into the bile duct alongside the guidewire. Before insertion of the sphincterotome, it was curved to direct the cutting wire to the 6 o'clock position on the papilla to allow it to be used as a push-type sphincterotome. ES was then performed. When selective cannulation was not possible, we performed precutting using a needle knife (PR-233Q or KD-10Q-1, Olympus Medical Systems). When deep cannulation could not be achieved despite attempting various techniques for approximately $60 \mathrm{~min}$, the procedure was terminated.

When failed cannulation, we scheduled the percutaneous transhepatic (PTBD) rendezvous technique, followed by with the transpapillary approach as a salvage procedure in another session. A percutaneous transhepatic puncture was performed under transabdominal ultrasonographic guidance. The patients were initially placed in a supine position. After needle puncture into the intrahepatic bile duct, a 5-Fr sheath was inserted over the guidewire into the bile duct and a $0.035^{\prime \prime}$ guidewire was then advanced through the papilla. The patients were then placed in a semiprone position and the DBE was advanced to the papilla to perform ERCP. When the rendezvous technique was used, we placed a 6-Fr nasobiliary tube into the bile duct for $24 \mathrm{~h}$ to prevent bile-induced peritonitis after the procedure.

In cases with bile duct stones, we performed papillary balloon dilation (Hurricane or CRE Esophageal/Pyloric, Boston Scientific Japan, Tokyo, Japan) in combination with ES using a conventional sphincterotome or needle knife to enable a reliable approach to the bile duct. Basket catheter, retrieval balloon catheter, and/or mechanical lithotriptor 


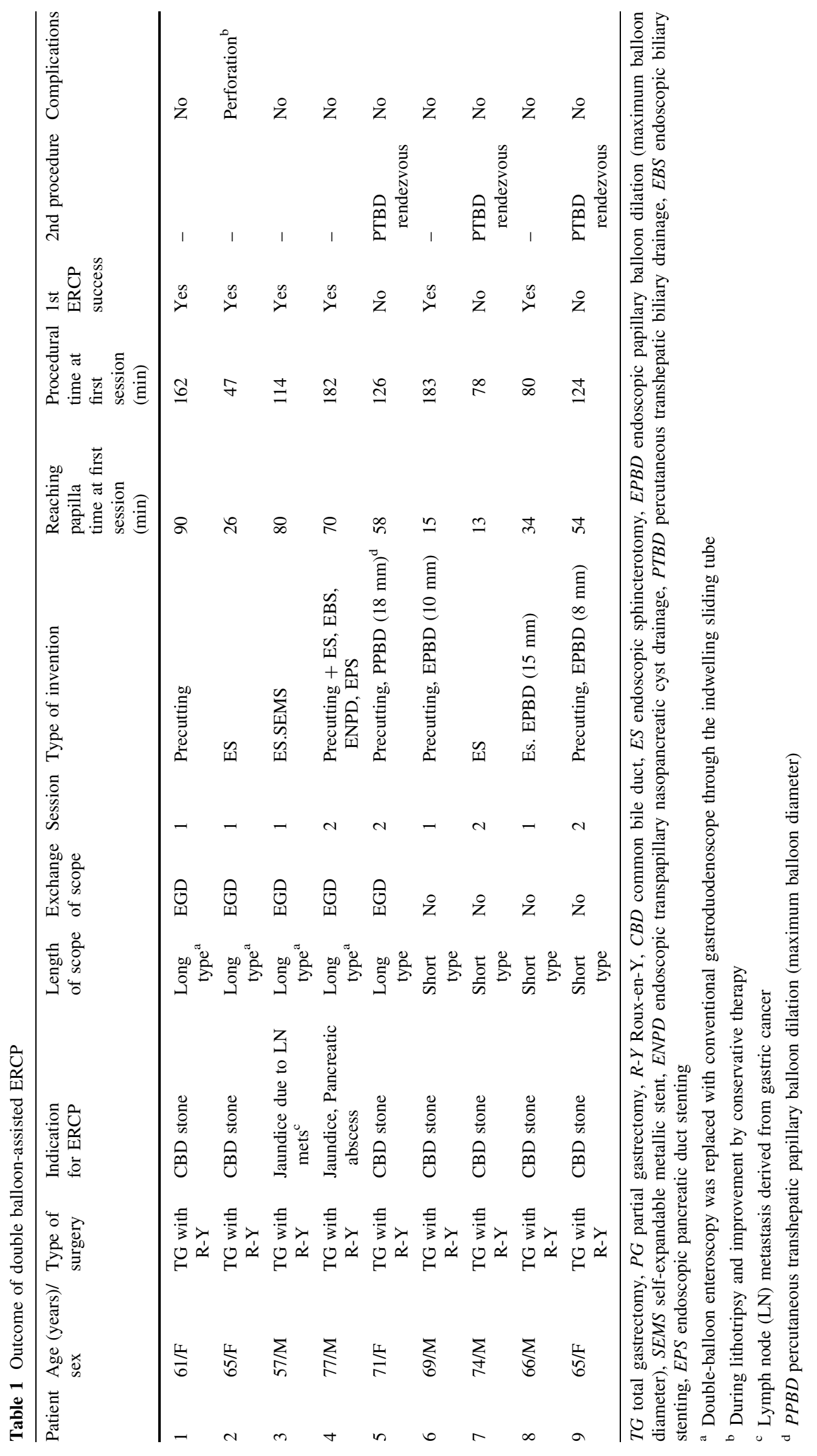


Table 2 Specifications of two-types double-balloon endoscopes

\begin{tabular}{lll}
\hline Therapeutic enteroscope & EN-450T5 & EC-450BI5 \\
\hline Direction of view & $\begin{array}{c}\text { Forward- } \\
\text { viewing } \\
140^{\circ}\end{array}$ & $\begin{array}{c}\text { Forward- } \\
\text { viewing } \\
140^{\circ}\end{array}$ \\
Angle of view & 9.4 & 9.4 \\
Outer diameter (mm) & 9.3 & 9.3 \\
Distal end & & \\
Insertion end & $180^{\circ} / 160^{\circ}$ & $180^{\circ} / 160^{\circ}$ \\
Bending section & $160^{\circ} / 160^{\circ}$ & $160^{\circ} / 160^{\circ}$ \\
Up/down & 2000 & 1520 \\
Right/left & 2300 & 1820 \\
Working length (mm) & 2.8 & 2.8 \\
Total length (mm) & TS-13140 & TS-13101 \\
Working channel diameter (mm) & 13.2 & 13.2 \\
\hline Overtube & 10.8 & 10.8 \\
\hline Outer diameter (mm) & 1350 & 950 \\
Inner diameter (mm) & 1450 & 1050 \\
Working length (mm) & Polyurethane & Polyurethane \\
Total length (mm) & Latex & Latex \\
Tube material & & \\
Balloon material & 250 & \\
\hline
\end{tabular}

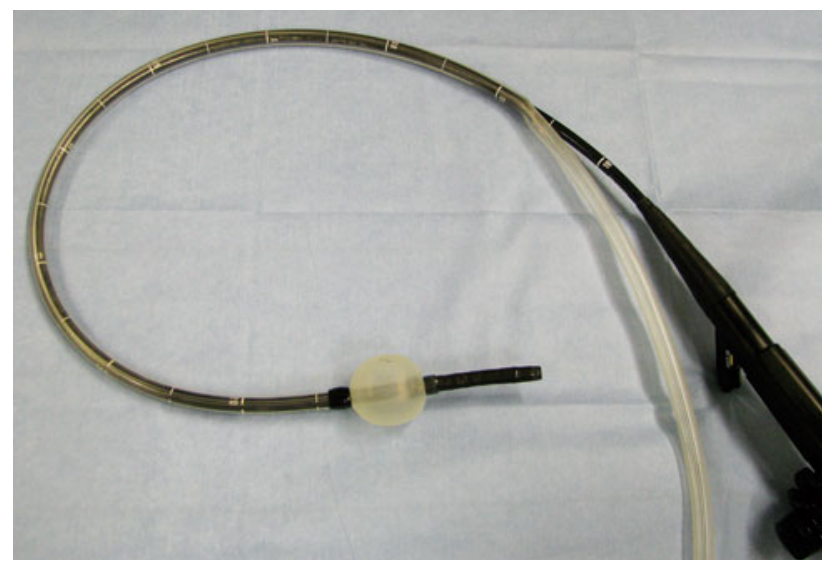

Fig. 1 Aperture approximately $12 \mathrm{~mm}$ was made in the overtube at a point $100 \mathrm{~cm}$ from its tip on the side opposite to the pressure line, to enable the balloon to remain inflated, for possible insertion of a conventional forward-viewing upper endoscope

(BML-V232QR-30, Olympus) were used for removal of stones.

\section{Statistical analysis}

Statistical analysis was performed by the chi-square test or Fisher's exact test for noncontinuous variables and the Student $t$ test for continuous variables. $P<0.05$ was regarded as indicating a statistically significant difference. Statistical analyses were performed with StatMate III (ATMS Co Ltd, Tokyo, Japan).

\section{Results}

Table 1 summarizes the results of DBE procedures. In nine patients, five long-type scopes and four short-type scopes were used for the DBE technique. The mean procedural time at first session was 121.8 (range, 47-182) min. In all cases, the papilla was reached. The mean time required to reach the papilla was 48.9 (range, 13-90) min. There was a statistically significant difference in the mean time to reach the papilla between the short and long enteroscopes $(29 \pm 19.2 \mathrm{~min}$ vs. $64.8 \pm 24.7 \mathrm{~min}$, respectively; $P=$ 0.044). In all five cases in which a long-type scope was used, the major papilla could be seen on reinsertion of a conventional forward-viewing upper endoscope.

The success rate of bile duct cannulation, resulting in achieving therapeutic ERCP on the first session was $66.7 \%$ (6/9). The mean procedural time of the successful group at the first session was 128 (range, 47-183) min. Precutting was used for bile duct cannulation on the first session in five cases (56\%). In three of these cases, bile duct cannulation was successful. In the remaining two cases, in which catheters could not be advanced into the bile duct, the PTBD rendezvous technique was used to enable therapeutic ERCP on the second session. Therapeutic ERCP was achieved in all nine cases.

In four of seven cases with bile duct stones, papillary balloon dilation was performed in addition to ES or precutting (Fig. 2). In one case (case 5), because transpapillary retrograde balloon dilation was difficult, antegrade balloon dilation via the PTBD route was performed. Complete stone clearance was achieved and confirmed by cholangiography using a retrieval balloon catheter or direct cholangioscopy.

An uncovered self-expandable metallic stent (SEMS) (Zilva, 10-mm diameter, 6-cm long, Wilson-Cook Medical Inc., Winston-Salem, NC) was successfully placed across the biliary stricture after ES in a patient with lymph node metastasis (case 3) (Fig. 3). In a patient with obstructive jaundice and pancreatic abscess (case 4), ERCP showed pancreatic duct stenosis and a pancreatic cyst. We eventually succeeded in placing a 5-Fr biliary stent in the bile duct and a 5-Fr pigtail-type nasocystic drainage tube in the pancreatic cyst.

There was one adverse event (case 2) in which a retroperitoneal perforation occurred during lithotripsy after endoscopic sphincterotomy. The patient was managed nonoperatively. 
Fig. 2 A Cholangiogram shows two bile duct stones. B X-ray film shows papillary dilation using a large balloon catheter. C Basket catheter was inserted in the large biliary orifice.

D Bile duct stone was removed without crushing
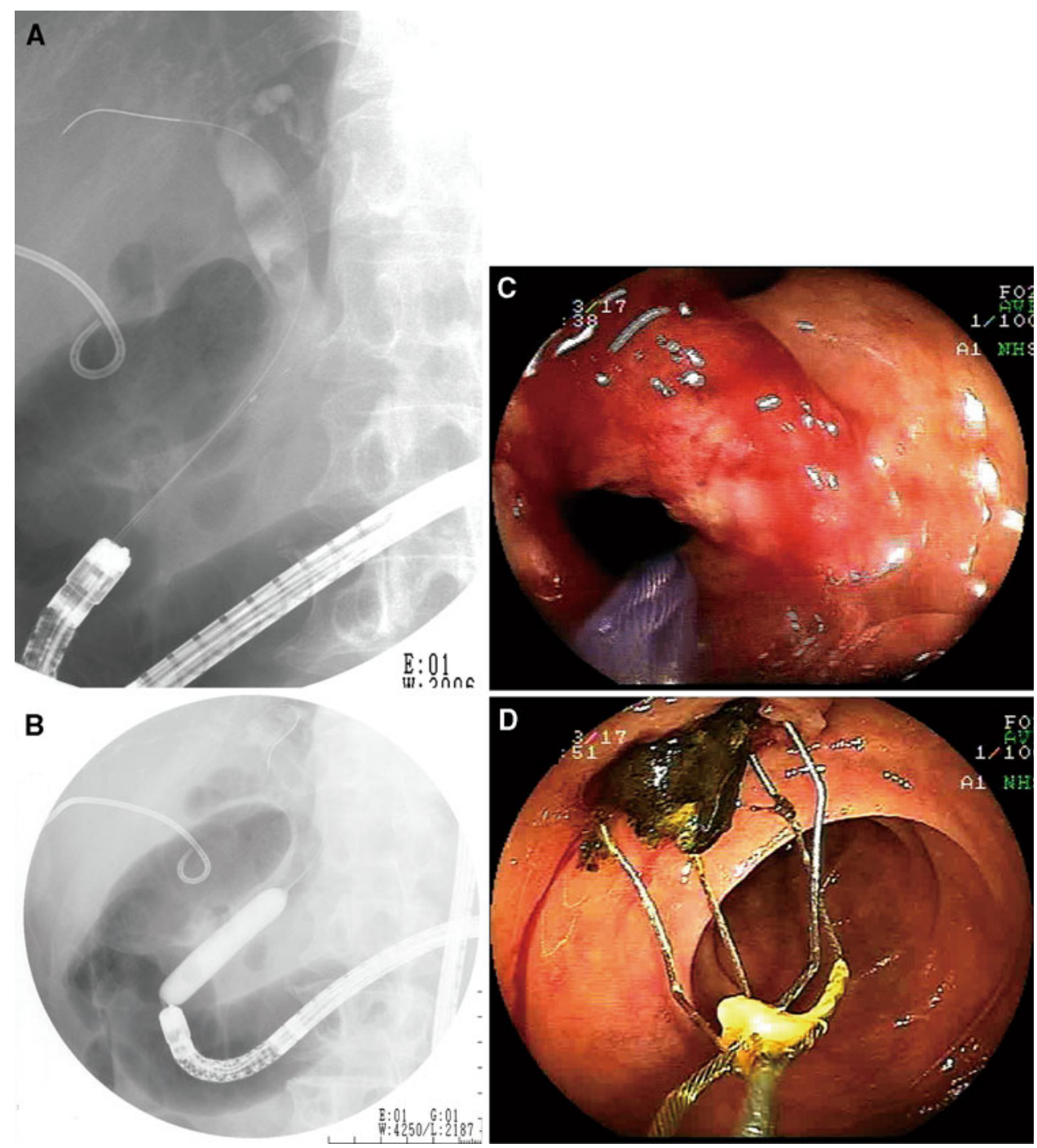

\section{Discussion}

There have been a few previous reports on attempted ERCP in patients with Roux-en-Y anastomosis and an intact papilla [3-9]. Wright et al. [6] revealed that once the major papilla was accessed with a duodenoscope (67\%: $10 / 15)$, therapeutic ERCP was feasible in all cases (100\%), although previous data described that only $8(57 \%)$ of 14 attempts to cannulate an intact papilla via a Roux-en-Y anastomosis could be successful [4, 5, 7-9].

However, recently developed DBE systems have made it possible to reach the papilla or biliopancreatoenteric anastomosis site with certainty even in patients with Roux-en-Y surgical anastomoses [10-23] (Table 3). In particular, sharp angulation of the Roux limb in any given case may make it difficult to negotiate the passage of the scope to the papilla even for skilled endoscopists. Then, the longer and thinner DBE may be more effective than a standard adult or pediatric colonoscope in navigating to the papilla or anastomotic site. Interestingly, Baron reported the option of using the DBE to place a percutaneous endoscopic gastrostomy tube in the resected stomach through which a duodenoscope can be passed [24].

In the present study, we could advance the DBE to the papilla in all cases. There was a statistically significant difference in the mean time to reach the papilla for the short and long scopes. We think there are two reasons for this: (1) the short-type DBE may have better maneuverability than the long-type DBE; (2) when we used the longtype DBE, it took some additional time because the DBE had to be replaced by a conventional forward-viewing upper endoscope; (3) the endoscopist (TI) was able to improve his technique through the initial five long-type DBE cases. In relation to this, one report on DBE has described that there was a significant learning curve, because there was a significant decline in overall procedure 
Fig. 3 A Cholangiogram shows a biliary stricture. B Endoscopic sphincterotomy was performed. C Uncovered metallic stent was placed. D X-ray shows correct positioning of the metallic stent
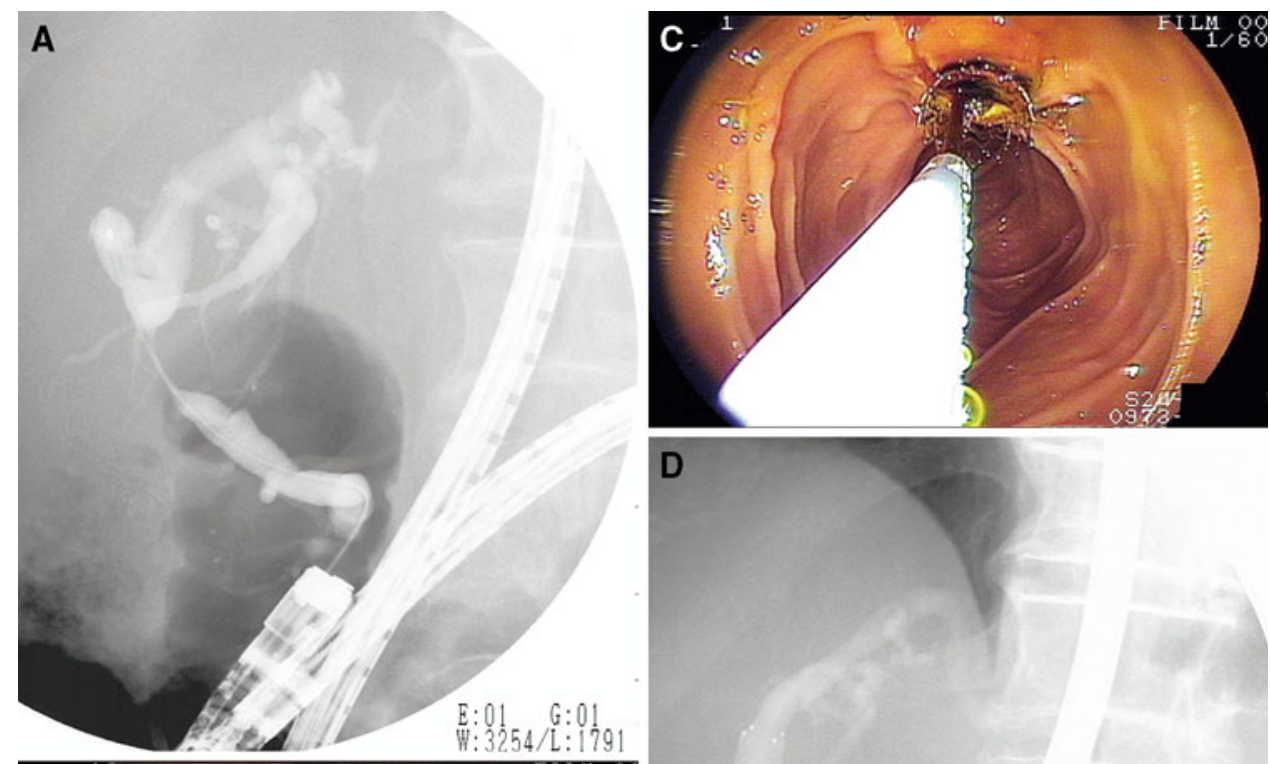

D
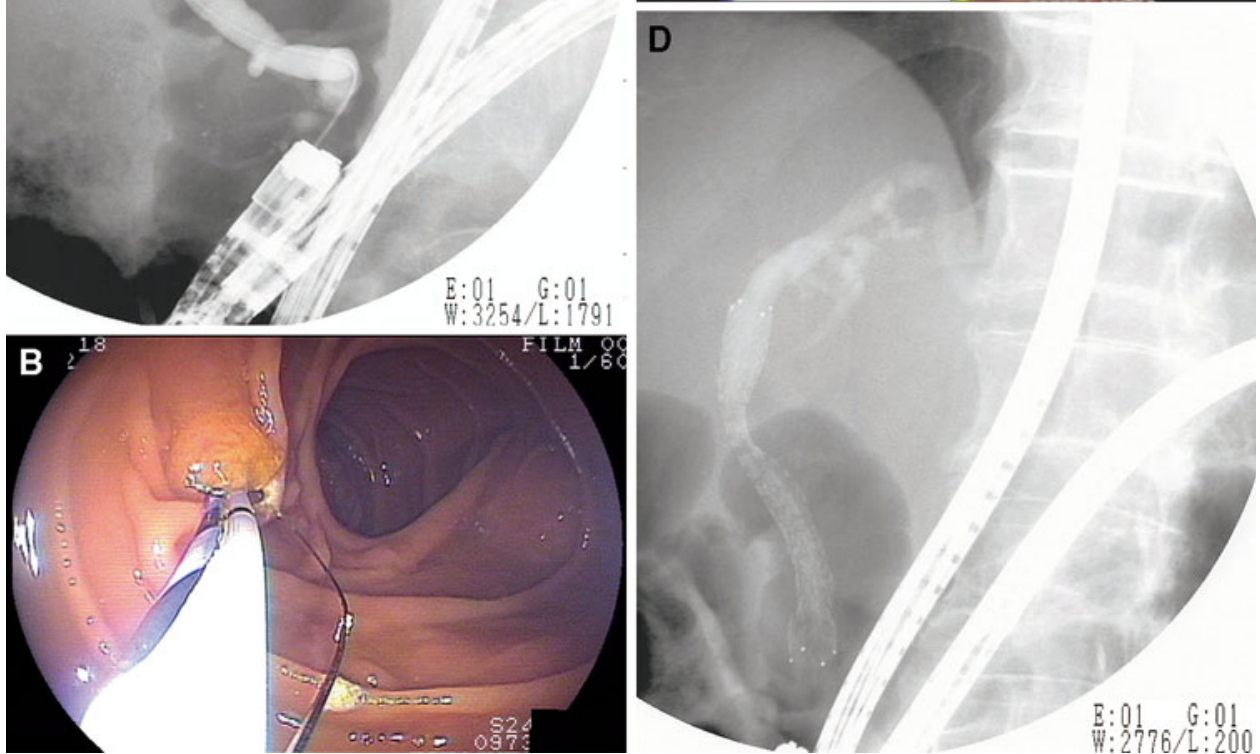

time and fluoroscopic time after the initial ten DBE cases, although these included not only biliopancreatic cases but also a large number of diseases of the small intestine [11]. With regard to intubation time, Aabakken et al. reported that the mean intubation time to reach the end of the Roux limb was 40 (range, 5-120) minutes [15], and these data are similar to ours $(48.9 \mathrm{~min})$. Although short-type DBE could reach the papilla in the present study, we should evaluate whether short-type DBE is enough for reaching the papilla in patients with long limb after Roux-en-Y gastric bypass for morbid obesity in the near future.

In cases of anastomosis, if there is an intact papilla, there are several hurdles for successful DBE-assisted ERCP: (1) absence of a side-viewing endoscope or an instrument elevator mechanism, making selective duct cannulation more difficult than standard ERCP; (2) the maneuverability of DBE is poor, particularly due to torsion of the shaft of the scope, loop formation, and bending of the tip of the scope, which render the introduction of accessories through the working channel difficult or impossible. Although complete elimination of loop formation would simplify the subsequent procedure because of possible better transmission of the rotating force of the scope or advancing the accessory in 1:1 force transmission
[21], loop elimination often is anatomically impossible due to adhesion, or forced elimination can cause perforation. (3) Types of accessories are limited, in particular those usable with the long DBE. Specially designed longer accessories have recently become commercially available or can be made to order in some countries but not Japan. However, the variety of devices available is insufficient for routine clinical work. In terms of accessories, this problem may be solved by using a short DBE or replacing a DBE with a conventional forward-viewing upper endoscope in almost all cases, because more conventional accessories can be used with these shorter scopes. (4) Narrow working channels also limit DBE-assisted therapeutic ERCP. DBE must be developed with a large working channel, and a large overtube (maximum $14 \mathrm{~mm}$ in diameter) through which duodenoscope exchange could be performed [12].

Interestingly, we found that a method closely resembling our approach to replacing the DBE with a $110-\mathrm{cm}$ long conventional forward-viewing upper endoscope by incision of the fixed overtube had been reported by Fähndrich et al. [22]. Care has to be taken that the pressure line for the balloon remains intact to prevent spontaneous deflation of the balloon. Nevertheless, there is still risk in pulling the balloon back to the oral side because strong 
Table 3 Review of double-balloon-assisted ERCP

\begin{tabular}{|c|c|c|c|c|c|c|c|c|}
\hline Author & Year & $\begin{array}{l}\text { Total } \\
\text { no. of } \\
\text { cases }\end{array}$ & $\begin{array}{l}\text { No. of } \\
\text { intact } \\
\text { papilla }\end{array}$ & Types of surgery & $\begin{array}{l}\text { Success rate of } \\
\text { reaching papilla/ } \\
\text { pancreatobiliary } \\
\text { anastomosis }\end{array}$ & $\begin{array}{l}\text { Success rate of } \\
\text { cannulation for intact } \\
\text { papilla/ } \\
\text { pancreatobiliary } \\
\text { anastomosis }\end{array}$ & Type of intervention & $\begin{array}{l}\text { Major } \\
\text { complication }\end{array}$ \\
\hline Haruta & 2005 & 1 & 0 & OLT with CJS & NA/ $100 \%$ & NA/ $100 \%$ & $\begin{array}{l}\text { Repeated balloon } \\
\text { dilation of stenotic } \\
\text { hepaticojejunostomy }\end{array}$ & - \\
\hline Mehdizadeh & 2006 & 5 & 2 & $\begin{array}{l}\text { HJS (1), OLT with } \\
\text { HJS (1) }\end{array}$ & $50 \% / 67 \%$ & $0 \% / 100 \%$ & $\begin{array}{l}\text { Balloon dilation of } \\
\text { stenotic } \\
\text { hepaticojejunostomy }\end{array}$ & - \\
\hline Emmett & 2007 & 14 & 6 & $\begin{array}{l}\text { Whipple with HJS (1) } \\
\text { or CJS (1),PJS (1), } \\
\text { Frey (1) }\end{array}$ & $\begin{array}{l}\text { 100\%/NA } \\
(85 \% \text { in } 20 \text { total } \\
\text { ERCP cases })\end{array}$ & $\begin{array}{c}88 \% / \mathrm{NA}(80 \% \text { in } 20 \\
\text { total ERCP cases) }\end{array}$ & $\begin{array}{l}\text { Balloon dilation, } \\
\text { sphincterotomy, } \\
\text { biliary stenting, } \\
\text { pancreatic stenting }\end{array}$ & - \\
\hline Moreeis & 2007 & 1 & 0 & HJS & NA/ $100 \%$ & NA/ $100 \%$ & $\begin{array}{l}\text { Balloon dilation of } \\
\text { stenotic } \\
\text { hepaticojejunostomy } \\
\text { biliary stenting }\end{array}$ & - \\
\hline Spahn & 2007 & 1 & 0 & HJS & NA/ $100 \%$ & NA/ $100 \%$ & $\begin{array}{l}\text { Balloon dilation of } \\
\text { stenotic } \\
\text { hepaticojejunostomy } \\
\text { stone removal }\end{array}$ & - \\
\hline Aabakken & 2007 & 13 & 1 & $\begin{array}{l}\text { OLT with HJS (10), } \\
\text { CDS (1), HJS (1), } \\
\text { PG (1) }\end{array}$ & $\begin{array}{l}94 \% \text { in } 18 \text { total } \\
\text { ERCP cases }\end{array}$ & $\begin{array}{r}0 \% / \mathrm{NA} \text { ( } 85 \% \text { in } 17 \\
\text { total ERCP cases) }\end{array}$ & $\begin{array}{l}\text { Biliary stent placement } \\
\text { and removal; stone } \\
\text { removal }\end{array}$ & - \\
\hline Chu & 2008 & 1 & 0 & CJS & NA/ $100 \%$ & NA/ $100 \%$ & Metallic stent removal & - \\
\hline Mönkemüller & 2008 & 2 & 1 & TG (1), Whipple (1) & $100 \% / 100 \%$ & $100 \% / 100 \%$ & $\begin{array}{l}\text { Biliary stenting, } \\
\text { removal Balloon } \\
\text { dilation, biliary } \\
\text { stenting }\end{array}$ & - \\
\hline Maasser & 2008 & 9 & 2 & $\begin{array}{l}\text { PG (1), PG with CDS (1), } \\
\text { TG (1), CJS (2), } \\
\text { Whipple (2), HJS (1), } \\
\text { DPPHR with CJS }\end{array}$ & $100 \% / 100 \%$ & $100 \% / 57 \%$ & $\begin{array}{l}\text { Balloon dilation, } \\
\text { sphincterotomy, } \\
\text { biliary stenting, stone } \\
\text { removal, bile } \\
\text { aspiration }\end{array}$ & - \\
\hline Koornstra & 2008 & 3 & 0 & $\begin{array}{l}\text { HJS (1), OLT with } \\
\text { HJS (2) }\end{array}$ & NA/ $100 \%$ & NA/67\% & Balloon dilation & - \\
\hline Zuber-Jerger & 2008 & 1 & 0 & $\begin{array}{l}\text { HJS for post-OLT } \\
\text { biliary stricture }\end{array}$ & NA/ $100 \%$ & NA/ $100 \%$ & NA (only contrast) & - \\
\hline Kuga & 2008 & 6 & 2 & $\begin{array}{l}\text { TG (1), GB (1), } \\
\text { HJS (3), CJS (1) }\end{array}$ & $100 \% / 100 \%$ & $100 \% / 83 \%$ & $\begin{array}{l}\text { Balloon dilation, } \\
\text { sphincterotomy, } \\
\text { biliary stenting, } \\
\text { stone removal }\end{array}$ & - \\
\hline Fähndrich & 2008 & 3 & 2 & $\begin{array}{l}\text { PPPD, modified B-II } \\
\text { with R-Y (2) }\end{array}$ & $100 \% / 100 \%$ & $100 \% / 100 \%$ & $\begin{array}{l}\text { Sphincterotomy, biliary } \\
\text { stenting, stone } \\
\text { removal }\end{array}$ & - \\
\hline Pohl & 2009 & 15 & 0 & CJS & NA/ $100 \%$ & NA/84\% & $\begin{array}{l}\text { Balloon dilation, biliary } \\
\text { stenting, stone } \\
\text { removal }\end{array}$ & - \\
\hline Present study & 2009 & 9 & 9 & TG (8), PG (1) & $100 \% / \mathrm{NA}$ & $67 \%(100 \%)^{\mathrm{b}} / \mathrm{NA}$ & $\begin{array}{l}\text { Biliary stenting, } \\
\text { stone removal, } \\
\text { ENPD, EBS, EPS }\end{array}$ & Perforation $^{\mathrm{a}}$ \\
\hline
\end{tabular}

$O L T$ orthotopic liver transplantation, $R-Y$ Roux-en-Y, HJS hepatojejunostomy, $C D S$ choledochodenostomy, $C J S$ choledochojejunostomy, $G B$ gastric bypass, $P G$ partial gastrectomy, $T G$ total gastrectomy, $D P P H R$ duodenum-preserving pancreatic head resection, $P P D$ pylorus-preserving pancreatoduodectomy, $B$-II Billroth-II, EBS endoscopic biliary stenting, EPS endoscopic pancreatic duct stenting, ENPD endoscopic nasopancreatic cyst drainage

a $100 \%$ of diagnostic cholangiography

${ }^{\mathrm{b}}$ First session $57 \%$, first plus second session $100 \%$, improvement by conservative therapy 
resistance occurs when reinserting through the angulated portion of the overtube. Although replacing the DBE with an upper endoscope is not completely reliable and can be cumbersome, major advantages include the ability to use standard accessories.

Before the introduction of double balloon enteroscopes, the next nonsurgical option after failed ERCP in patients with Roux-en-Y anastomosis was to perform PTBD. This often required placement of a relatively large size external tube [18]. In the present study, we conducted the rendezvous technique of placement of a temporary guidewire. The percutaneous approach may be technically difficult in the absence of dilated bile ducts or contraindicated because of large volume ascites and use of clotting disorders. In addition, the percutaneous approach does not usually allow access to the pancreatic ductal system [18]. However, PTBD is reliable in allowing access to the biliary tree compared with attempting another endoscopic session using the same technique.

Other than one perforation, no major complications have been reported using DBE for ERCP (Table 3). However, the actual rates of perforation, bleeding, and pancreatitis using DBE-assisted ERCP in large numbers of patients is unknown.

Recently, there are a few small case reports on the single-balloon enteroscopy (SBE)-assisted ERCP [25, 26], although SBE has only long-type scope. There may be several hurdles for successful SBE-assisted ERCP as well as DBE-assisted ERCP.

In conclusion, DBE-assisted ERCP appears to be a promising method for performing therapeutic ERCP in patients with a Roux-en-Y anastomosis and intact papilla. Further development of the accessories for use in balloon enteroscope systems is still needed.

Acknowledgment The authors are indebted to Prof. J. Patrick Barron of the International Medical Communication Center of Tokyo Medical University for his review of this manuscript.

Disclosures Drs, Takao Itoi, Kentaro Ishii, Atsushi Sofuni, Fumihide Itokawa, Takayoshi Tsuchiya, Toshio Kurihara, Shujiro Tsuji, Nobuhito Ikeuchi, Katsumasa Fukuzawa, Fuminori Moriyasu, and Akihiko Tsuchida have no conflicts of interest or financial ties to disclose.

Open Access This article is distributed under the terms of the Creative Commons Attribution Noncommercial License which permits any noncommercial use, distribution, and reproduction in any medium, provided the original author(s) and source are credited.

\section{References}

1. Haber GB (2007) Double balloon endoscopy for pancreatic and biliary access in altered anatomy (with video). Gastrointest Endosc 66(3 Suppl):S47-S50
2. Yamamoto H, Sekine Y, Sato Y, Higashizawa T, Miyata T, Iino S, Ido K, Sugano K (2001) Total enteroscopy with a nonsurgical steerable double balloon method. Gastrointest Endosc 53:216220

3. Gostout CJ, Bender CE (1988) Cholangiopancreatography, sphincterotomy, and common bile duct stone removal via Rouxen-Y limb enteroscopy. Gastroenterology 95:156-163

4. Hinze RE, Adler A, Veltzke H, Abou-Rhbyeh H (1997) Endoscopic access to the papilla of vater for endoscopic retrograde cholangiopancreatography in patients with Billroth II or Roux-enY gastrojejunostomy. Endoscopy 29:69-73

5. Elton E, Hanson BL, Qaseem T, Howell DA (1998) Diagnostic and therapeutic ERCP using an enteroscope and a pediatric colonoscope in long-limb surgical bypass patients. Gastrointest Endosc 47:62-67

6. Wright BE, Cass OW, Freeman ML (2002) ERCP in patients with long-limb Roux-en-Y gastrojejunostomy and intact papilla. Gastrointest Endosc 56:225-232

7. Baron TH, Vickers SM (1998) Surgical gastrostomy placement as access for diagnostic and therapeutic ERCP. Gastrointest Endosc 48:640-641

8. Hintze RE, Adler A, Veltzke W, Abou-Rebyeh H (1997) Endoscopic sphincterotomy using an S-shaped sphincterotome in patients with Billroth II or Roux-en-Y gastrojejunostomy. Endoscopy 29:74-78

9. Mosca S, Uomo G, Ceglia T, Galasso G (1998) Is it always true that ERCP cannot be carried out in patients with Roux-en-Y gastrojejunostomy [letter?]. Endoscopy 30:870

10. Haruta H, Yamamoto H, Mizuta K, Kita Y, Uno T, Egami S, Hishikawa S, Sugano K, Kawarasaki H (2005) A case of successful enteroscopic balloon dilation for late anastomotic stricture of choledochoduodenostomy after living donor liver transplantation. Liver Transpl 11:1608-1610

11. Mehdizadeh S, Ross A, Gerson L, Leighton J, Chen A, Schembre D, Chen G, Semrad C, Kamal A, Harrison EM, Binmoeller K, Waxman I, Kozarek R, Lo SK (2006) What is the learning curve associated with double-balloon enteroscopy? Technical details and early experience in 6 U.S. tertiary care centers. Gastrointest Endosc 64:740-750

12. Emmett DS, Mallat DB (2007) Double-balloon ERCP in patients who have undergone Roux-en-Y surgery: a case series. Gastrointest Endosc 66:1038-1041

13. Moreeis TG, Roth B, Vandervliet EJ, Parizel PM, Dutre J, Peickmans PA (2007) The use of the double-balloon enteroscope for endoscopic retrograde cholangiopancreatography and biliary stent placement after Roux-en-Y hepaticojejunostomy. Endoscopy 39(Suppl 1):E196-E197

14. Spahn TW, Grosse-Thie W, Spies P, Mueller MK (2007) Treatment of choledocholithiasis following Roux-en-Y hepaticojejunostomy using double-balloon endoscopy. Digestion 75 : $20-21$

15. Aabakken L, Bretthauer M, Line PD (2007) Double-balloon enteroscopy for endoscopic retrograde cholangiography in patients with a Roux-en-Y anastomosis. Endoscopy 39:10681071

16. Chu YC, Yang CC, Yeh YH, Chen CH, Yueh SK (2008) Doubleballoon enteroscopy application in biliary tract disease-its therapeutic and diagnostic functions. Gastrointest Endosc 68: $585-591$

17. Mönkemüller K, Bellutti M, Neumann H, Malfertheiner P (2008) Therapeutic ERCP with the double-balloon enteroscope in patients with Roux-en-Y anastomosis. Gastrointest Endosc 67: 992-996

18. Maasser C, Lenze F, Bokemeyer M, Ullerich H, Domagk D, Bruewer M, Luegering A, Domschke W, Kucharzik T (2008) Double balloon enteroscopy: a useful tool for diagnostic and 
therapeutic procedures in the pancreaticobiliary system. Am J Gastroenterol 103:894-900

19. Koornstra JJ (2008) Double balloon enteroscopy for endoscopic retrograde cholangiopancreaticography after Roux-en-Y reconstruction: case series and review of the literature. Neth $\mathbf{J}$ Med 66:275-279

20. Zuber-Jerger I, Klebl F, Schoelmerich J (2008) Endoscopic retrograde cholangiography of a hepaticojejunostomy using doubleballoon enteroscopy. Dig Surg 25:241-243

21. Kuga R, Furuya CK Jr, Hondo FY, Ide E, Ishioka S, Sakai P (2008) ERCP using double-balloon enteroscopy in patients with Roux-en-Y anatomy. Dig Dis 26:330-335

22. Fähndrich M, Sandmann M, Heik M (2008) A facilitated method for endoscopic interventions at the bile duct after Roux-en-Y reconstruction using double balloon enteroscopy. Z Gastroenterol $46: 335-338$
23. Pohl J, May A, Aschmoeneit I, Ell C (2009) Double-balloon endoscopy for retrograde cholangiography in patients with choledochojejunostomy and Roux-en-Y reconstruction [Germany with English abstract]. Z Gastroenterol 47:215-219

24. Baron TH (2006) Double-balloon enteroscopy to facilitate retrograde PEG placement as access for therapeutic ERCP in patients with long-limb gastric bypass. Gastrointest Endosc 64:973-974

25. Mönkemüller K, Fry LC, Bellutti M, Neumann H, Malfertheiner P (2008) ERCP using single-balloon instead of double-balloon enteroscopy in patients with Roux-en-Y anastomosis. Endoscopy 40:E19-E20

26. Dellon ES, Kohn GP, Morgan DR, Grim IS (2008, Nov 7) Endoscopic retrograde cholangiopancreatography with singleballoon enteroscopy is feasible in patients with a prior Roux-en-Y anastomosis. Dig Dis Sci 54:1798-1803 